\title{
The Key Role of Ozone-Depleting Substances in Weakening the Walker Circulation in the Second Half of the Twentieth Centuryo
}

\author{
LORENZO M. POLVANI \\ Department of Applied Physics and Applied Mathematics, Department of Earth and Environmental Sciences, \\ and Lamont-Doherty Earth Observatory, Columbia University, New York, New York \\ KATINKA BELLOMO \\ Lamont-Doherty Earth Observatory, Columbia University, Palisades, New York
}

(Manuscript received 29 December 2017, in final form 18 September 2018)

\begin{abstract}
It is widely appreciated that ozone-depleting substances (ODS), which have led to the formation of the Antarctic ozone hole, are also powerful greenhouse gases. In this study, we explore the consequence of the surface warming caused by ODS in the second half of the twentieth century over the Indo-Pacific Ocean, using the Whole Atmosphere Chemistry Climate Model (version 4). By contrasting two ensembles of chemistryclimate model integrations (with and without ODS forcing) over the period 1955-2005, we show that the additional greenhouse effect of ODS is crucial to producing a statistically significant weakening of the Walker circulation in our model over that period. When ODS concentrations are held fixed at 1955 levels, the forcing of the other well-mixed greenhouse gases alone leads to a strengthening —rather than weakening-of the Walker circulation because their warming effect is not sufficiently strong. Without increasing ODS, a surface warming delay in the eastern tropical Pacific Ocean leads to an increase in the sea surface temperature gradient between the eastern and western Pacific, with an associated strengthening of the Walker circulation. When increasing ODS are added, the considerably larger total radiative forcing produces a much faster warming in the eastern Pacific, causing the sign of the trend to reverse and the Walker circulation to weaken. Our modeling result suggests that ODS may have been key players in the observed weakening of the Walker circulation over the second half of the twentieth century.
\end{abstract}

\section{Introduction}

The formation of the ozone hole over the second half of the twentieth century is well understood to have resulted from increased anthropogenic emissions of halogenated trace gases such as chlorofluorocarbons [see Solomon (1999) for a review]. Pressing concerns about potentially harmful levels of surface UV radiation from a thinning ozone layer resulted in the signing of the Montreal Protocol, an international ban on emissions of ozone-depleting substances (ODS), which went into effect in 1989, with several subsequent amendments. Moreover, it is well known that ODS are

Supplemental information related to this paper is available at the Journals Online website: https://doi.org/10.1175/JCLID-17-0906.s1.

Corresponding author: L. M. Polvani, lmp@columbia.edu powerful greenhouse gases (Velders et al. 2007). In this paper we show that the considerable radiative forcing of ODS may have played a crucial role in determining trends in sea surface temperature (SST), sea level pressure (SLP), and circulation patterns in the tropical Indo-Pacific Ocean over the period 19552005.

The Indo-Pacific Ocean is characterized by a cold tongue in the eastern side of the Pacific Ocean and a warm pool that straddles the Indian and Pacific Oceans. This east-west gradient in SST is responsible for the overturning Walker circulation, with air rising over the warm pool and descending over the cold tongue. The Walker circulation affects wind stress, ocean dynamics, and clouds, and it can thus have major climatic impacts. A strengthening of the Walker circulation is believed to be a key driver of the recent warming hiatus (Kosaka and Xie 2013; de Boisséson et al. 2014; England et al. 2014; McGregor et al. 2014; Douville et al. 2015). 
Many modeling studies have suggested that the Walker circulation will weaken in coming decades in response to increasing greenhouse gases (Held and Soden 2006; Vecchi and Soden 2007; Chadwick et al. 2013; He et al. 2014). It has proven difficult to establish a clear weakening over the observational record, however; this is due, in part, to the fact that the Walker circulation is affected by modes of internal climate variability—for example, Pacific decadal variabilitythat can affect trends in the Walker circulation for many years (Sohn and Park 2010; Sohn et al. 2013; L'Heureux et al. 2013; Sandeep et al. 2014). While many studies have suggested that the Walker circulation has weakened as a consequence of anthropogenic forcings since the beginning of the twentieth century (e.g., Vecchi et al. 2006; Deser et al. 2010; Gastineau and Soden 2011; DiNezio et al. 2013), others have reached different conclusions, in particular regarding the period from 1950 to present for which the sign of the trend in the Walker circulation varies among studies depending on the dataset or the methodology used to compute the circulation trends (Luo et al. 2012; Meng et al. 2012; Wang et al. 2012; L'Heureux et al. 2013; Sandeep et al. 2014; Kociuba and Power 2015; Latif et al. 2015).

Part of the difficulty in establishing a robust Walker circulation trend in the observations may be due to the small signal relative to noise (Bordbar et al. 2017), owing to cancellations among different anthropogenic forcings in the presence of large internal variability. Specifically, in analyzing coupled climate model integrations with and without increasing ODS, we show that the pattern of SST and SLP caused by ODS opposes the transient effect of the other greenhouse gases alone [notably carbon dioxide $\left.\left(\mathrm{CO}_{2}\right)\right]$ in the second half of the twentieth century and is key to obtaining a weakening of the Walker circulation in our model. This result highlights a previously unappreciated impact of ODS on the climate system.

\section{Data and methods}

We analyze integrations performed with the Community Earth System Model (CESM1) in the Whole Atmosphere Chemistry Climate Model, version 4 (WACCM4), configuration, fully documented by Marsh et al. (2013). The atmospheric component WACCM4with a horizontal resolution of $1.9^{\circ} \times 2.5^{\circ}$ and 66 vertical levels with a model top near $140 \mathrm{~km}$-is coupled to the identical land, ocean, and sea ice components as the low-top version of CESM1 (Gent et al. 2011). In addition, WACCM includes interactive chemistry for stratospheric ozone, which is important for a consistent treatment of the role of ODS on the climate system. It is important to note that WACCM4 is a state-of-the-art Earth system model that participated in phase 5 of the Climate Model Intercomparison Project (CMIP5; Taylor et al. 2012).

Two ensembles of WACCM4 integrations, each comprising six members, were carried out over the period 1955-2005. The first ensemble consists of standard "historical" CMIP5 integrations, with all natural and anthropogenic forcings prescribed, including ODS emissions. We will refer to this ensemble as the "All Forcings" runs. The second ensemble, hereinafter referred to as "Fixed ODS," is identical to the first in all respects except the surface concentrations of ODS, which are held fixed at 1955 levels throughout the integrations. The impact of ODS on the Southern Ocean using these two ensembles has been previously reported in Solomon et al. (2016), who showed how ODS are responsible for over $80 \%$ of the modeled changes in the meridional overturning circulation (and over $30 \%$ of the temperature and salinity changes in the Southern Ocean) over the period 1955-2005. In this paper we focus on the tropical Indo-Pacific region.

We emphasize that all members in each ensemble are forced identically and differ solely in their atmospheric initial conditions [in the spirit of Deser et al. (2012)]: we thus interpret the ensemble mean trends as the forced response, the ensemble spread as a measure of internal climate variability, and the difference between the means of the two ensembles as the effect of ODS. Note that attribution is immediate and unambiguous in this case, since the only forcing difference between the two ensembles is the time evolution of ODS emissions. For many variables of interest we compute simple linear trends from 1955 to 2005, and in most of the figures below we will show these linear trends multiplied by the number of years (51): this result will be referred to as "the change" for each run or, when averaged across an ensemble or runs, as "the response." Results are considered to be robust when at least 5 of 6 ensemble members agree on the sign of the trend (indicated by stippling in the figures).

\section{Results}

We start by quantifying, in the context of all anthropogenic forcings, the greenhouse warming caused by ODS alone over the tropical Indo-Pacific region. In Fig. 1 we show the time series of annual mean SST anomalies over the tropical Pacific (averaged over $30^{\circ} \mathrm{S}-$ $30^{\circ} \mathrm{N}$ and $125^{\circ} \mathrm{E}-70^{\circ} \mathrm{W}$ ) from 1955 to 2005 for the All Forcings (blue) and Fixed ODS (red) integrations; thick curves show the two ensemble means, and thin ones show the individual members. It is immediately 


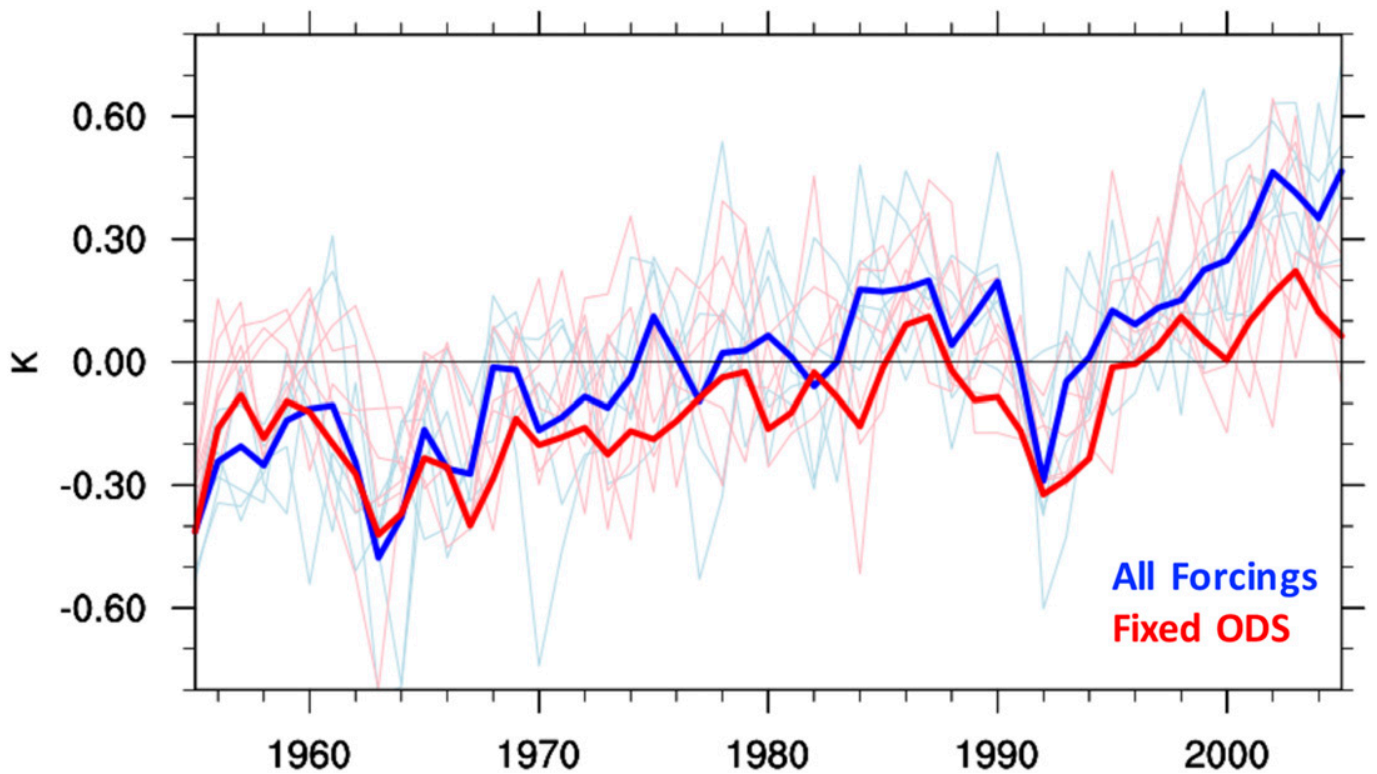

FIG. 1. Annual mean SST anomalies averaged over the tropical Pacific $\left(30^{\circ} \mathrm{S}-30^{\circ} \mathrm{N}, 125^{\circ} \mathrm{E}-70^{\circ} \mathrm{W}\right)$. Annual anomalies are obtained after removing the seasonal cycle from monthly means and then computing annual means from the deseasonalized monthly anomalies. Thin blue curves indicate All Forcings integrations; thin red curves indicate Fixed ODS integrations. The thick curves are the corresponding ensemble means.

apparent that in the absence of changing ODS the tropical Pacific SST trend is considerably smaller than when ODS are increasing. Specifically, the response of SST over the period 1955-2005 (computed as trend multiplied by the number of years) in the Fixed ODS ensemble mean is $0.38^{\circ} \mathrm{C}$ but grows to $0.62^{\circ} \mathrm{C}$ in the All Forcings ensemble mean: the additional $0.24^{\circ} \mathrm{C}$ warming is due to ODS. This already highlights a large impact on SST as a result of ODS forcing.

To illustrate the robustness of this result, Table 1 shows that the two ensemble mean responses are well separated, and that internal variability across the ensemble is relatively small. In fact, the smallest change in the All Forcings ensemble $\left(0.51^{\circ} \mathrm{C}\right)$ is bigger than the greatest change in the Fixed ODS ensemble $\left(0.41^{\circ} \mathrm{C}\right)$. Uncertainty is further assessed from the standard deviation across the six members of each ensemble (italics in Table 1), confirming that the two ensembles do not overlap. In summary: ODS contribute nearly $40 \%\left(0.24^{\circ}\right.$ of $0.62^{\circ} \mathrm{C}$ ) of the total SST warming of the tropical $\mathrm{Pa}$ cific over 1955-2005 in our model.

While this result may appear surprising, it is entirely consistent with the previous studies that have demonstrated that ODS are powerful greenhouse gases.

TABLE 1. Tropical Pacific SST change ( $\Delta$ SST) in each ensemble (Ens) member and, for the ensemble mean, over 1955-2005 (columns) for the All Forcings and Fixed ODS experiments. Boldface values indicate the smallest and biggest SST changes for each experiment. VSST is the change in the gradient of SST over 1955-2005, and - VSLP is the change in the gradient of SLP over 1955-2005 with a reversed sign. Gradients are computed as the difference between east $\left(5^{\circ} \mathrm{S}-5^{\circ} \mathrm{N}, 80^{\circ}-160^{\circ} \mathrm{W}\right)$ and west $\left(5^{\circ} \mathrm{S}-5^{\circ} \mathrm{N}, 80^{\circ}-160^{\circ} \mathrm{E}\right)$. In this sign convention, negative values indicate weakening of the gradients (El Niño like) and positive values indicate strengthening of the gradients (La Niña like). Uncertainty in the ensemble mean (in italics) is derived as the standard deviation computed from the ensemble spread.

\begin{tabular}{|c|c|c|c|c|c|c|c|}
\hline & Ens mean & Ens 1 & Ens 2 & Ens 3 & Ens 4 & Ens 5 & Ens 6 \\
\hline \multicolumn{8}{|l|}{$\Delta \mathrm{SST}$} \\
\hline All Forcings & $0.62 \pm 0.06$ & 0.61 & 0.67 & 0.65 & 0.51 & 0.62 & 0.65 \\
\hline Fixed ODS & $0.38 \pm 0.03$ & 0.39 & 0.37 & 0.32 & 0.40 & 0.37 & 0.41 \\
\hline \multicolumn{8}{|l|}{$\nabla \mathrm{SST}$} \\
\hline All Forcings & $0.04 \pm 0.35$ & 0.42 & 0.07 & -0.04 & -0.61 & 0.19 & 0.21 \\
\hline Fixed ODS & $-0.19 \pm 0.17$ & -0.20 & -0.15 & -0.18 & -0.00 & -0.11 & -0.51 \\
\hline \multicolumn{8}{|l|}{$-\nabla \mathrm{SLP}$} \\
\hline All Forcings & $0.09 \pm 0.41$ & 0.47 & 0.09 & 0.26 & -0.70 & 0.17 & 0.23 \\
\hline Fixed ODS & $-0.31 \pm 0.13$ & -0.35 & -0.44 & -0.33 & -0.10 & -0.21 & -0.44 \\
\hline
\end{tabular}


$\Delta \mathrm{SST}$

(a) All Forcings

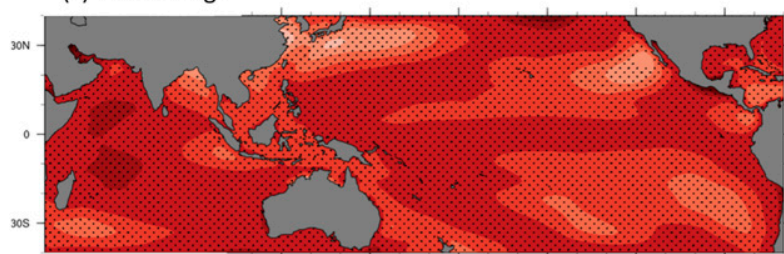

(b) Fixed ODS

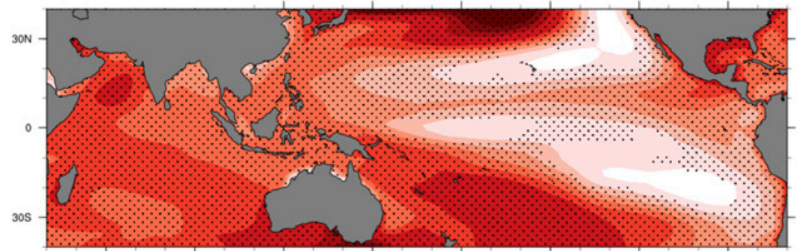

(c) All Forcings - Fixed ODS

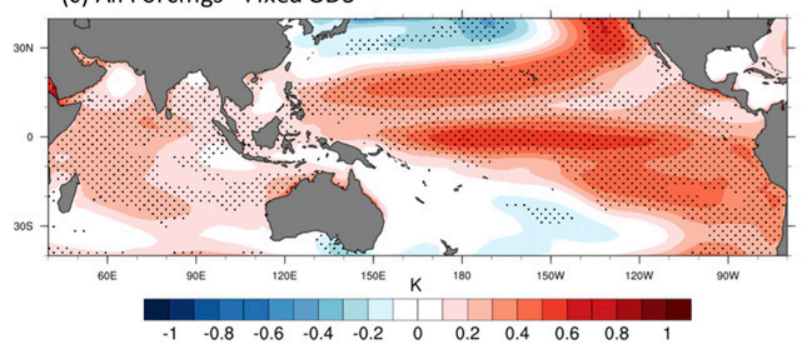

(d) All Forcings

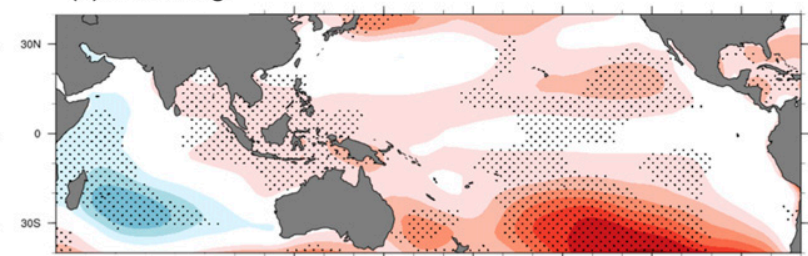

(e) Fixed ODS

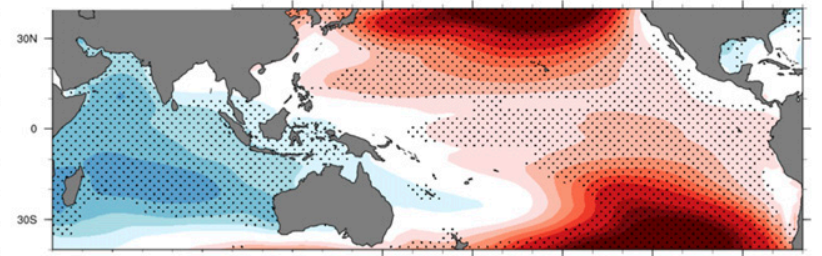

(f) All Forcings-Fixed ODS

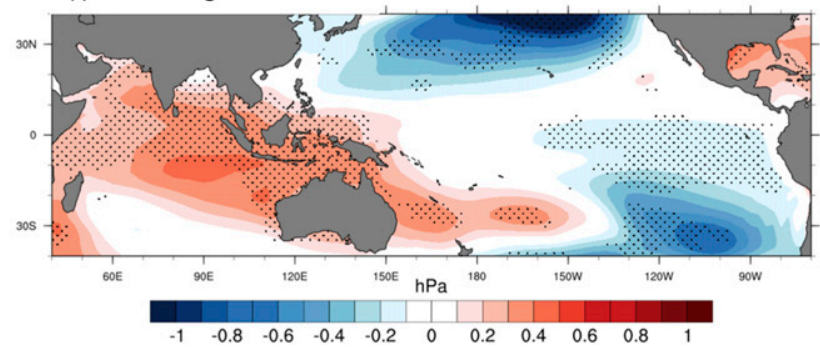

FIG. 2. Ensemble mean (left) SST (K) and (right) SLP (hPa) response over 1955-2005 for (a),(d) All Forcings, (b),(e) Fixed ODS, and (c),(f) All Forcings minus Fixed ODS. Regions where at least 5 of 6 ensemble members agree on the sign of the trends are stippled.

Computing the global mean surface temperature ${ }^{1}$ response over the same period, we find that ODS cause roughly $30 \%$ of the warming from 1955 to 2005, a somewhat smaller fraction than over the tropical Pacific. This increased warming from ODS follows from two facts. First, the radiative forcing from ODS is considerable, about $20 \%$ the $\mathrm{CO}_{2}$ value over the period 1960 2005; this can be seen, for instance, in the right panel of Fig. 2 of Velders et al. (2007). Second, ODS have a higher efficacy than $\mathrm{CO}_{2}$, about $30 \%$ higher according to Hansen et al. (2005). In fact, ODS appear to have the highest global warming efficacy of all greenhouse gases, according to the same study.

Beyond a considerable overall warming, however, it is the pattern of that warming over the Indo-Pacific region that is crucial for understanding the impact of ODS on the Walker circulation. That pattern is shown in the left column of Fig. 2: note how the larger warming in the All Forcings ensemble (Fig. 2a) relative to the Fixed ODS ensemble (Fig. 2b) is especially prominent in the eastern and central Pacific, as clearly seen in the difference plot

\footnotetext{
${ }^{1} \mathrm{We}$ note that the equilibrium climate sensitivity of the WACCM4 model is $2.73^{\circ} \mathrm{C}$ for a doubling of $\mathrm{CO}_{2}$ (Marsh et al. 2016), very much within the CMIP5 range (Forster et al. 2007).
}

(Fig. 2c). In the absence of ODS forcing (Fig. 2b), the SST gradient is considerable, showing a La Niña-like SST response. Such delayed SST warming in the eastern Pacific trade winds is not unexpected (e.g., Liu et al. 2005; Seager and Murtugudde 1997; DiNezio et al. 2009; Leloup and Clement 2009), and it is understood to result from the high trade wind speeds in that region, which increase the efficiency of the negative latent heat flux feedback in response to greenhouse gas warming. The key point here is that, when ODS are added to the forcings (Fig. 2a), the sign of the SST gradient nearly reverses, and the SST response becomes El Niño like (see Table 1).

Such a strong response in SST patterns yields a large response in SLP, shown in the right column of Fig. 2. It is clear that the additional warming pattern due to ODS (Fig. 2c) leads to a weakening of SLP in the east and strengthening of SLP in the west (Fig. 2f), opposing climatological means and resulting in a slight weakening of the Walker circulation (Fig. 2d). When ODS are held fixed, the SLP response indicates a strengthening of the Walker circulation (Fig. 2e) driven by the strengthening of the SST gradient (Fig. 2b). Therefore, increasing ODS are crucial in producing a weakening of the Walker circulation, over the period 1995-2005, in our model. 
(a) All Forcings

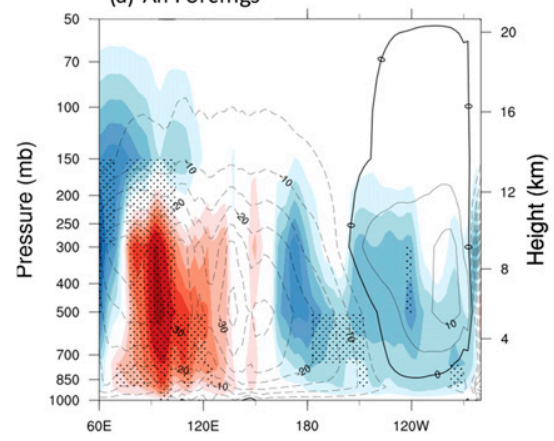

(b) Fixed ODS

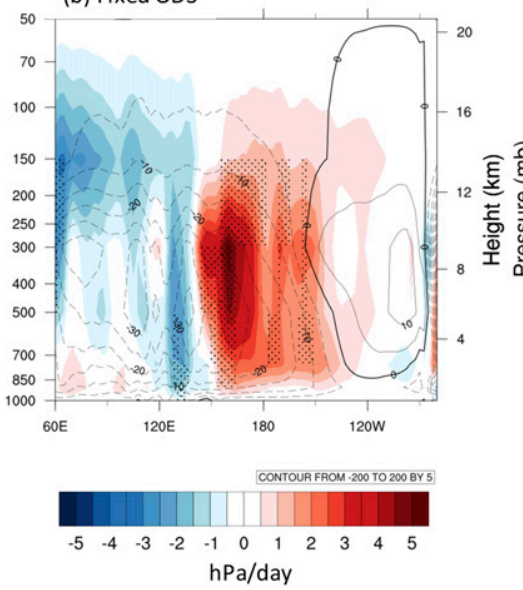

(c) All Forcings-Fixed ODS

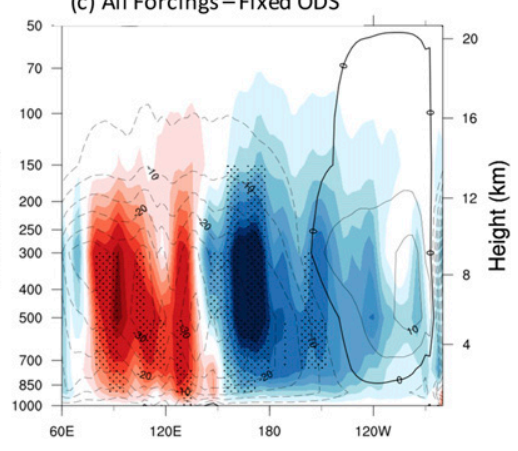

FIG. 3. Ensemble mean pressure velocity $\omega\left(\mathrm{hPa} \mathrm{day}^{-1}\right)$ response over $1955-2005$, averaged over $10^{\circ} \mathrm{S}-10^{\circ} \mathrm{N}$ : (a) All Forcings, (b) Fixed ODS, and (c) All Forcings minus Fixed ODS. Climatological values of $\omega$ are computed as the long-term mean of $\omega$ averaged over $10^{\circ} \mathrm{S}-$ $10^{\circ} \mathrm{N}$ and are superimposed as black contours. Contour levels range from -200 to $200 \mathrm{hPa} \mathrm{day}^{-1}$, with $5 \mathrm{hPa} \mathrm{day}^{-1}$ intervals. Stippling indicates that at least 5 of 6 ensemble members agree on sign of the trends.

For the reader who might wonder about the robustness of this result we note three things. First, the stippling in Fig. 2 marks the regions where at least 5 of 6 ensemble members agree on the sign of the trend. Second, from the actual values of SST and SLP gradientscomputed as east $\left(5^{\circ} \mathrm{S}-5^{\circ} \mathrm{N}, 80^{\circ}-160^{\circ} \mathrm{W}\right)$ minus west $\left(5^{\circ} \mathrm{S}-5^{\circ} \mathrm{N}, 80^{\circ}-160^{\circ} \mathrm{E}\right)$, in Table 1 -one can easily see a consistent reversal of trends signs as increasing ODS are added to the forcings. Third, for the sake of completeness, we include SST and SLP changes (as in Fig. 2) for each of the six individual members (see Figs. S1-S6 in the online supplemental material). With one exception (member 4), the patterns of SST and SLP gradients are the same across all members, suggesting that the forced response is robust despite large internal variability.

To further elucidate the impact of ODS on the Walker circulation we next examine the pressure velocity $\omega$ : its response over 1955-2005 is shown in Fig. 3a, averaged over $10^{\circ} \mathrm{S}-10^{\circ} \mathrm{N}$, as a function of height and longitude over the Indo-Pacific Ocean. The climatological values of $\omega$ are shown in black contours, negative (dashed) contours corresponding to regions of convection, and positive (solid) contours corresponding to regions of subsidence. In the All Forcings ensemble mean, the response in $\omega$ indicates a moderate weakening and

\footnotetext{
${ }^{2}$ In Figs. S7 and S8 in the online supplemental material, the SST and SLP response for the subperiods 1955-79 and 1980-2005 are shown (to satisfy the curiosity of one reviewer). The effect of ODS is still clearly visible in both of these shorter periods, but with some differences between the earlier one and the latter one. This is to be expected when taking trends over such short periods, given our relatively small ensemble size and the large internal variability.
}

eastward shift of the Walker circulation (Fig. 3a). Reduction in convection is seen in the western Pacific, and reduction in subsidence in the eastern Pacific, and an increase in convection in the central Pacific, around longitude $180^{\circ}$, indicating an eastward shift of the Walker circulation. All of these features are consistent with the Walker circulation response to greenhouse gases documented in previous studies (e.g., Vecchi and Soden 2007; DiNezio et al. 2009; Bellomo and Clement 2015). In contrast, in the Fixed ODS ensemble mean the response in $\omega$ shows a strengthening of the Walker circulation and a $\mathrm{La}$ Niña-like response (Fig. 3b). The difference between the All Forcings and Fixed ODS (Fig. 3c) ensemble means clearly illustrates the robust weakening of the Walker circulation as a result of the forcing from ODS in our model.

We conclude by showing the response in precipitation over the tropical Pacific in Fig. 4 (superimposed on the climatological values in black contours). As one might expect from the preceding figures, we find that precipitation resembles an El Niño-like increase in the equatorial Pacific in the All Forcings ensemble mean (Fig. 4a) but a La Niña-like decrease when ODS are held fixed over the same period (Fig. 4b). The effect of ODS (Fig. 4c), therefore, is to reverse the sign of the transient trend that is due to effect of the other wellmixed greenhouse gases. Unlike the other quantities, the response in precipitation is somewhat less robust (stippling): this is expected, as precipitation fields are usually noisier. Nevertheless, if we use 4 of 6 as a threshold for robustness, we find very good agreement across ensemble members (not shown). We would be able to show a more robust response if we had a larger 
(a) All Forcings

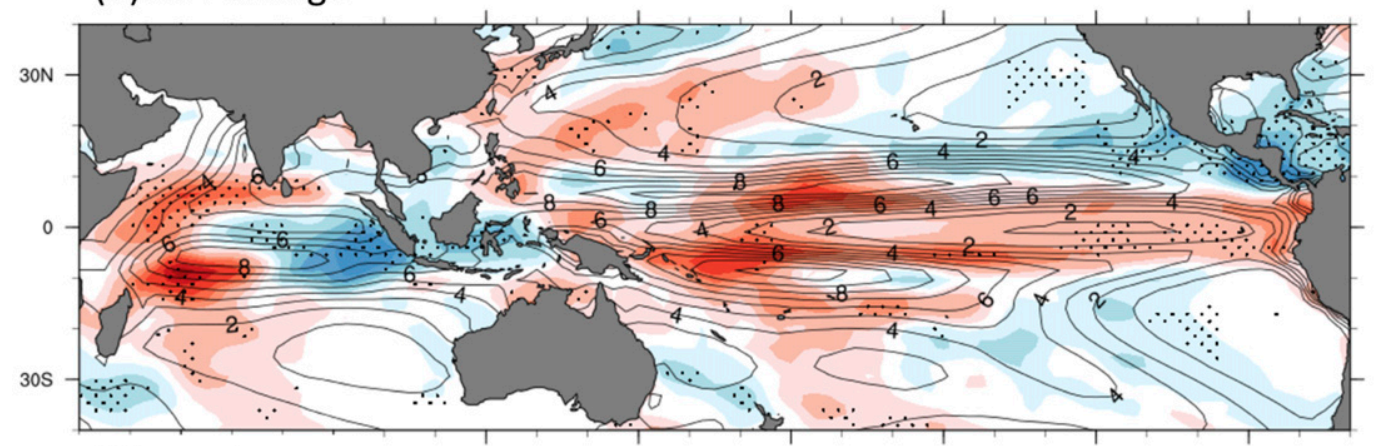

(b) Fixed ODS

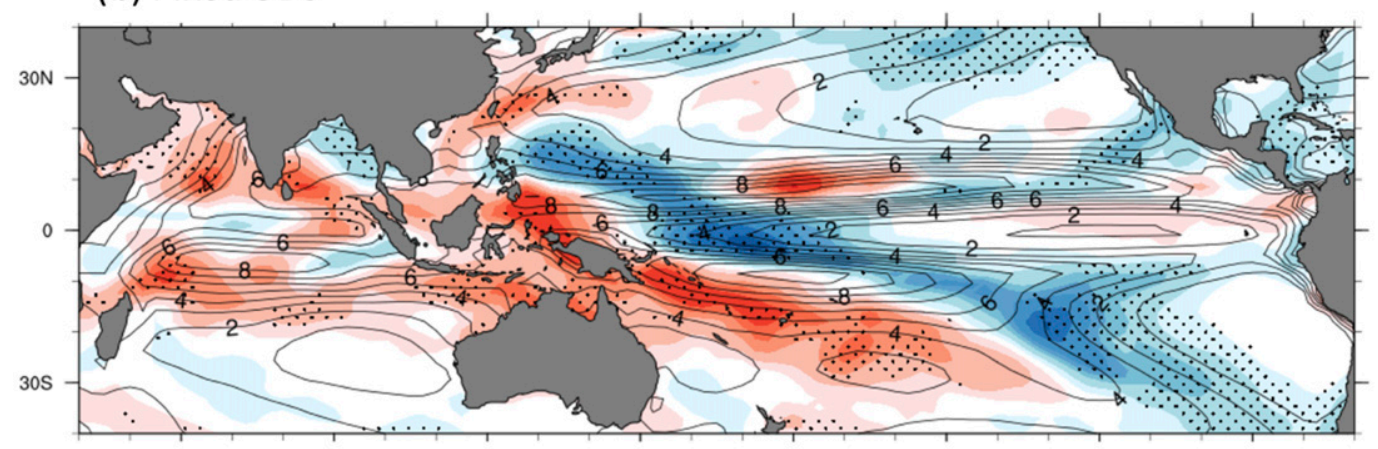

(c) All Forcings - Fixed ODS

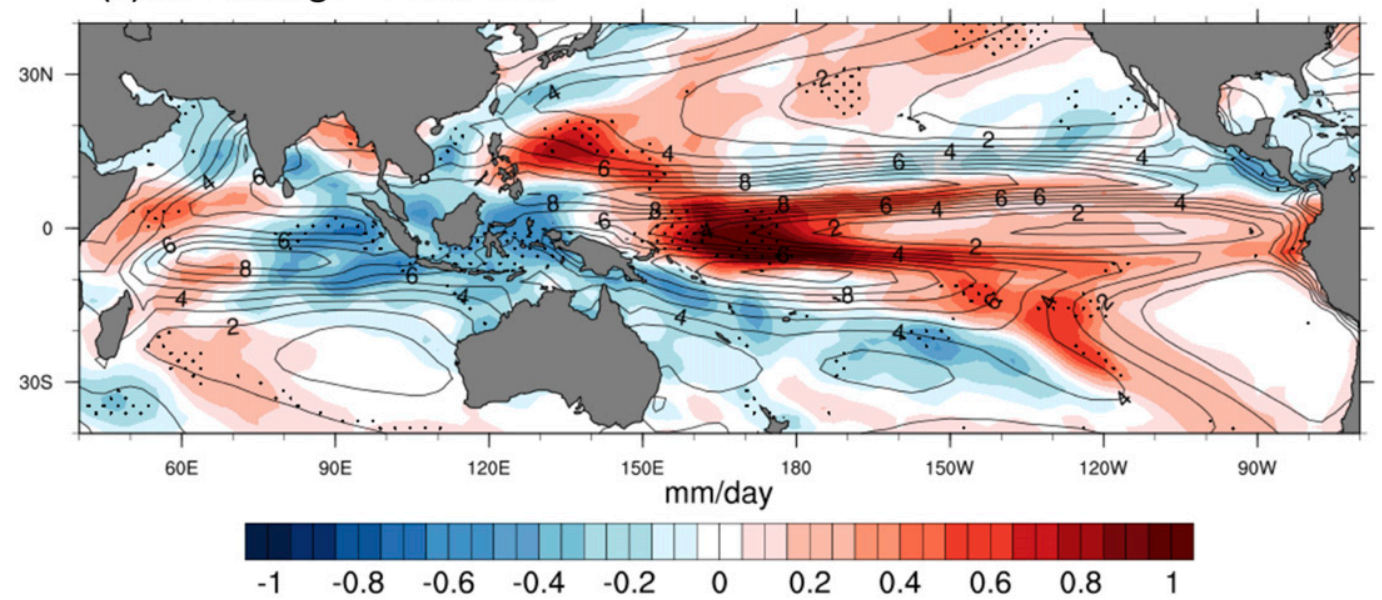

FIG. 4. Ensemble mean precipitation $\left(\mathrm{mm} \mathrm{day}^{-1}\right.$ ) response over 1955-2005: (a) All Forcings, (b) Fixed ODS, and (c) All Forcings minus Fixed ODS. Climatological values of precipitation computed as the long-term mean precipitation at each grid point are superimposed as black contours. Contour levels range from 0 to $12 \mathrm{~mm} \mathrm{day}^{-1}$, with $1 \mathrm{~mm} \mathrm{day}^{-1}$ intervals. Stippling indicates where at least 5 of 6 ensemble members agree on sign.

ensemble at our disposal, but coupled model integrations with interactive chemistry are computationally expensive.

\section{Summary and discussion}

With the help of specifically designed model integrations performed with a stratosphere-resolving coupled model with interactive ozone chemistry, we have explored the impact of ODS on trends in tropical Pacific SST, SLP, and atmospheric circulation in the second half of the twentieth century. We have found a surprisingly large, and previously undocumented, role for ODS on such trends in our model. This large impact of ODS has gone unnoticed until now because most studies usually lump ODS together with 
the other anthropogenic greenhouse gases, without isolating the individual components. Our results also highlight and confirm an important connection between the pattern of SST warming and the strength of the Walker circulation [previously suggested in Tokinaga et al. (2012) and Sandeep et al. (2014)].

Of course, our findings need to be taken with some caution since they have been obtained with a single climate model. It is, however, important to note that WACCM4 is a well-tested model whose climate simulations over the 1850-2005 period have been thoroughly vetted and found to be nearly identical to those of the low-top component of CESM1 (Marsh et al. 2013). Nonetheless, the precise quantitative impact of ODS on the tropical Pacific is likely to be model dependent. We are in the process of analyzing similar sets of integrations (with and without ODS forcings) from a different climate model: preliminary results are very encouraging, showing a very substantial contribution from ODS to the warming of the tropical eastern and central Pacific in the second half of the twentieth century. Further details will be reported in a future paper.

One might ask whether the large impact of ODS documented above is mediated by stratospheric ozone loss or whether it simply follows from the direct radiative surface warming caused by ODS. We cannot answer that question definitively here, because stratospheric ozone is interactively computed in our model and cannot be prescribed independent of ODS. However, simple considerations lead us to believe that the role of ozone is likely to be minor. First, the largest ozone losses are found at the poles (notably the South Pole): tropical ozone losses are relatively small in comparison. Second, it is well established that the radiative forcing associated with stratospheric ozone is minuscule in comparison with the radiative forcing from halocarbons (see, e.g., Fig. 2.20 of IPCC 2013). Third, ozone depletion has a very distinct seasonal character, and thus its impacts on the climate system are also clearly seasonal [see Previdi and Polvani (2014) for many examples of this effect]. Since we have found little seasonality in the tropical Pacific response to ODS, the direct radiative effect of these very substances is likely the dominant mechanism. Model integrations separating the effect of ozone and ODS will be carried out in the near future to confirm this mechanism.

Acknowledgments. Author LMP is grateful for continued support from the U.S. National Science Foundation. Author KB is funded by a cooperative agreement between NASA and Columbia University. The computations were carried out with high-performance computing support provided by NCAR's Computational and
Information Systems Laboratory, which is sponsored by the National Science Foundation. The data produced for and analyzed in this paper are archived on the High Performance Storage System (HPSS) at the National Center for Atmospheric Research and can be provided upon request.

\section{REFERENCES}

Bellomo, K., and A. C. Clement, 2015: Evidence for weakening of the Walker circulation from cloud observations. Geophys. Res. Lett., 42, 7758-7766, https://doi.org/10.1002/2015GL065463.

Bordbar, M. H., T. Martin, M. Latif, and W. Park, 2017: Role of internal variability in recent decadal to multidecadal tropical Pacific climate changes. Geophys. Res. Lett., 44, 4246-4255, https://doi.org/10.1002/2016GL072355.

Chadwick, R., P. Wu, P. Good, and T. Andrews, 2013: Asymmetries in tropical rainfall and circulation patterns in idealised $\mathrm{CO}_{2}$ removal experiments. Climate Dyn., 40, 295-316, https:// doi.org/10.1007/s00382-012-1287-2.

de Boisséson, E., M. A. Balmaseda, S. Abdalla, E. Källén, and P. A. E. M. Janssen, 2014: How robust is the recent strengthening of the tropical Pacific trade winds? Geophys. Res. Lett., 41, 4398-4405, https://doi.org/10.1002/2014GL060257.

Deser, C., A. S. Phillips, and M. A. Alexander, 2010: Twentieth century tropical sea surface temperature trends revisited. Geophys. Res. Lett., 37, L10701, https://doi.org/10.1029/ 2010GL043321.

,,-- V. Bourdette, and H. Teng, 2012: Uncertainty in climate change projections: The role of internal variability. Climate Dyn., 38, 527-546, https://doi.org/10.1007/s00382-010-0977-x.

DiNezio, P. N., A. C. Clement, G. A. Vecchi, B. J. Soden, B. P. Kirtman, and S.-K. Lee, 2009: Climate response of the equatorial Pacific to global warming. J. Climate, 22, 4873-4892, https://doi.org/10.1175/2009JCLI2982.1.

_ G. A. Vecchi, and A. C. Clement, 2013: Detectability of changes in the Walker circulation in response to global warming. J. Climate, 26, 4038-4048, https://doi.org/10.1175/ JCLI-D-12-00531.1.

Douville, H., A. Voldoire, and O. Geoffroy, 2015: The recent global warming hiatus: What is the role of Pacific variability? Geophys. Res. Lett., 42, 880-888, https://doi.org/10.1002/ 2014 GL062775.

England, M. H., and Coauthors, 2014: Recent intensification of wind-driven circulation in the Pacific and the ongoing warming hiatus. Nat. Climate Change, 4, 222-227, https://doi.org/ 10.1038/nclimate2106.

Forster, P., and Coauthors, 2007: Changes in atmospheric constituents and in radiative forcing. Climate Change 2007: The Physical Science Basis, S. Solomon et al., Eds., Cambridge University Press, 129-234, http://www.ipcc.ch/pdf/ assessment-report/ar4/wg1/ar4-wg1-chapter2.pdf.

Gastineau, G., and B. J. Soden, 2011: Evidence for a weakening of tropical surface wind extremes in response to atmospheric warming. Geophys. Res. Lett., 38, L09706, https://doi.org/ 10.1029/2011GL047138.

Gent, P. R., and Coauthors, 2011: The Community Climate System Model version 4. J. Climate, 24, 4973-4991, https://doi.org/ 10.1175/2011JCLI4083.1.

Hansen, J. E., and Coauthors, 2005: Efficacy of climate forcings. J. Geophys. Res., 110, D18104, https://doi.org/10.1029/ 2005JD005776. 
He, J., B. J. Soden, and B. Kirtman, 2014: The robustness of the atmospheric circulation and precipitation response to future anthropogenic surface warming. Geophys. Res. Lett., 41, 2614 2622, https://doi.org/10.1002/2014GL059435.

Held, I. M., and B. J. Soden, 2006: Robust responses of the hydrological cycle to global warming. J. Climate, 19, 5686-5699, https://doi.org/10.1175/JCLI3990.1.

IPCC, 2013: Summary for policymakers. Climate Change 2013: The Physical Science Basis, T. F. Stocker et al., Eds., Cambridge University Press, 1-29, http://www.climatechange2013.org/spm.

Kociuba, G., and S. B. Power, 2015: Inability of CMIP5 models to simulate recent strengthening of the Walker circulation: Implications for projections. J. Climate, 28, 20-35, https://doi.org/ 10.1175/JCLI-D-13-00752.1.

Kosaka, Y., and S.-P. Xie, 2013: Recent global-warming hiatus tied to equatorial Pacific surface cooling. Nature, 501, 403-407, https://doi.org/10.1038/nature12534.

Latif, M., V. A. Semenov, and W. Park, 2015: Super El Niños in response to global warming, in a climate model. Climatic Change, 132, 489-500, https://doi.org/10.1007/s10584-015-1439-6.

Leloup, J., and A. Clement, 2009: Why is there a minimum in projected warming in the tropical North Atlantic Ocean? Geophys. Res. Lett., 36, L14802, https://doi.org/10.1029/ 2009GL038609.

L'Heureux, M. L., S. Lee, and B. Lyon, 2013: Recent multidecadal strengthening of the Walker circulation across the tropical Pacific. Nat. Climate Change, 3, 571-576, https://doi.org/10.1038/ nclimate1840.

Liu, Z., S. Vavrus, F. He, N. Wen, and Y. Zhong, 2005: Rethinking tropical ocean response to global warming: The enhanced equatorial warming. J. Climate, 18, 4684-4700, https://doi.org/ 10.1175/JCLI3579.1.

Luo, J.-J., W. Sasaki, and Y. Masumoto, 2012: Indian Ocean warming modulates Pacific climate change. Proc. Natl. Acad. Sci. USA, 109, 18701-18 706, https://doi.org/10.1073/pnas.1210239109.

Marsh, D. R., M. J. Mills, D. E. Kinnison, J.-F. Lamarque, N. Calvo, and L. M. Polvani, 2013: Climate change from 1850 to 2005 simulated in CESM1(WACCM). J. Climate, 26, 73727391, https://doi.org/10.1175/JCLI-D-12-00558.1.

_ - J.-F. Lamarque, A. J. Conley, and L. M. Polvani, 2016: Stratospheric ozone chemistry feedbacks are not critical for the determination of climate sensitivity in CESM1(WACCM). Geophys. Res. Lett., 43, 3928-3934, https://doi.org/10.1002/2016GL068344.

McGregor, S., A. Timmermann, M. F. Stuecker, M. H. England, M. Merrifield, F.-F. Jin, and Y. Chikamoto, 2014: Recent Walker circulation strengthening and Pacific cooling amplified by Atlantic warming. Nat. Climate Change, 4, 888-892, https:// doi.org/10.1038/nclimate2330.

Meng, Q., M. Latif, W. Park, N. S. Keenlyside, V. A. Semenov, and T. Martin, 2012: Twentieth century Walker circulation change:
Data analysis and model experiments. Climate Dyn., 38, $1757-$ 1773, https://doi.org/10.1007/s00382-011-1047-8.

Previdi, M., and L. M. Polvani, 2014: Climate system response to stratospheric ozone depletion and recovery. Quart. J. Roy. Meteor. Soc., 140, 2401-2419, https://doi.org/10.1002/qj.2330.

Sandeep, S., F. Stordal, P. D. Sardeshmukh, and G. P. Compo, 2014: Pacific Walker circulation variability in coupled and uncoupled climate models. Climate Dyn., 43, 103-117, https:// doi.org/10.1007/s00382-014-2135-3.

Seager, R., and R. G. Murtugudde, 1997: Ocean dynamics, thermocline adjustment, and regulation of tropical SST. J. Climate, 10, 521-534, https://doi.org/10.1175/1520-0442(1997)010<0521: ODTAAR $>2.0 . \mathrm{CO} ; 2$.

Sohn, B. J., and S.-C. Park, 2010: Strengthened tropical circulations in past three decades inferred from water vapor transport. J. Geophys. Res., 115, D15112, https://doi.org/ 10.1029/2009JD013713.

_ , S.-W. Yeh, J. Schmetz, and H.-J. Song, 2013: Observational evidences of Walker circulation change over the last 30 years contrasting with GCM results. Climate Dyn., 40, 1721-1732, https://doi.org/10.1007/s00382-012-1484-z.

Solomon, A., L. M. Polvani, D. W. Waugh, and S. M. Davis, 2016: Contrasting upper and lower atmospheric metrics of tropical expansion in the Southern Hemisphere. Geophys. Res. Lett. 43, 10 496-10 503, https://doi.org/10.1002/2016GL070917.

Solomon, S., 1999: Stratospheric ozone depletion: A review of concepts and history. Rev. Geophys., 37, 275-316, https://doi.org/ 10.1029/1999RG900008.

Taylor, K. E., R. J. Stouffer, and G. A. Meehl, 2012: An overview of CMIP5 and the experiment design. Bull. Amer. Meteor. Soc. 93, 485-498, https://doi.org/10.1175/BAMS-D-11-00094.1.

Tokinaga, H., S.-P. Xie, C. Deser, Y. Kosaka, and Y. M. Okumura, 2012: Slowdown of the Walker circulation driven by tropical Indo-Pacific warming. Nature, 491, 439-443, https://doi.org/ 10.1038/nature11576.

Vecchi, G. A., and B. J. Soden, 2007: Global warming and the weakening of the tropical circulation. J. Climate, 20, 43164340, https://doi.org/10.1175/JCLI4258.1.

,,-- A. T. Wittenberg, I. M. Held, A. Leetmaa, and M. J. Harrison, 2006: Weakening of tropical Pacific atmospheric circulation due to anthropogenic forcing. Nature, 441, 73-76, https://doi.org/10.1038/nature04744.

Velders, G. J., S. O. Andersen, J. S. Daniel, D. W. Fahey, and M. McFarland, 2007: The importance of the Montreal Protocol in protecting climate. Proc. Natl. Acad. Sci. USA, 104, 4814-4819, https://doi.org/10.1073/pnas.0610328104.

Wang, B., J. Liu, H.-J. Kim, P. Webster, and S.-Y. Yim, 2012: Recent change of the global monsoon precipitation (19792008). Climate Dyn., 39, 1123-1135, https://doi.org/10.1007/ s00382-011-1266-z. 